\title{
Identification of the structural and functional determinants of the extracellular domain of the human follicle stimulating hormone receptor
}

\author{
P S Kene, V C Nalavadi ${ }^{1}$, R R Dighe ${ }^{1}$, K S lyer and S D Mahale \\ Division of Structural Biology, National Institute for Research in Reproductive Health (ICMR), Jehangir Merwanji Street, Parel, Mumbai 400012 , India \\ ${ }^{1}$ Department of Molecular Reproduction, Development and Genetics, Indian Institute of Science, Bangalore-560 012, India \\ (Requests for offprints should be addressed to S D Mahale; Email: smitamahale@hotmail.com or peptidelab@rediffmail.com)
}

\begin{abstract}
The extracellular domain (ECD) of the human folliclestimulating hormone receptor (hFSHR) is believed to be the major determinant of hormone selectivity. Different discrete, discontinuous regions on the ECD of the hFSHR have been suggested to be crucial for hormone binding. However, the role of the ECD in signal transduction is not well understood. This study provides some insight into these aspects of the structure-function relationship of the ECD of hFSHR. Ten peptides were selected from the ECD on the basis of their ability to be surface oriented, synthesized by the solid-phase method using fluorenylmethyloxycarbonyl chemistry, purified and characterized. They were further studied for their ability to modulate both human follicle-stimulating hormone (hFSH)-FSHR
\end{abstract}

binding and cAMP generation. Competitive inhibition studies showed that, of all the peptides studied, peptides 285-300 and 297-310 hFSHR were able to inhibit hFSH binding to FSHR. Both peptides function as weak competitive inhibitors of hFSH-FSHR binding. Peptides 285 300 hFSHR, 216-235 hFSHR, 184-195 hFSHR, 79$89 \mathrm{hFSHR}$ and 15-31 hFSHR were observed to inhibit FSH-induced cAMP production. In summary, this study suggests that discrete, functional domains of the ECD have a role in hormone binding and signal transduction. Region 285-300 has been identified as a novel region crucial for both FSH binding and cAMP generation.

Journal of Endocrinology (2004) 182, 501-508

\section{Introduction}

Follicle-stimulating hormone (FSH) is secreted by the anterior pituitary and is central to mammalian reproduction. It is essential for the development of ovarian follicles beyond the antral stage in females (Richards 1980) and for the regulation of qualitative and quantitative spermatogenesis in males (Foulkes et al. 1993).

FSH binds specifically to follicle-stimulating hormone receptor (FSHR) present on the plasma membrane of granulosa cells in the ovary or Sertoli cells in the testis. Binding of FSH to its receptor induces signal transduction by stimulation of the adenylyl cyclase pathway and thereby regulates steroidogenesis (Reichert \& Dattatreyamurty 1989). Belonging to the family of G-protein-coupled receptors, the FSHR comprises an uncharacteristically large extracellular domain (ECD), a transmembrane domain and a short intracellular carboxy terminal tail. The structural biology of FSHR has been reviewed in detail by Dias and Van Roey (2001).

The ECD of glycoprotein hormone receptors has been shown to be the site of high-affinity hormone binding by the use of chimeric luteinizing hormone ( $\mathrm{LH}) / \mathrm{FSH}$ receptors (Braun et al. 1991) and also by expressing and studying the truncated luteinizing hormone receptor (LHR) comprising the ECD (Ji \& Ji 1991). The ECD of glycoprotein hormone receptors contains from eight to nine imperfect leucine-rich repeats (LRR), which are similar to those found in the structure of porcine ribonuclease inhibitor (RI) (McFarland et al. 1989, Kobe \& Deisenhofer 1994). The crystal structure analysis for RI shows each LRR to have a $\beta-\alpha$ hairpin unit structure resembling a horseshoe, with $\beta$-strands forming the inner circumference and the $\alpha$-helices forming the outer circumference. Based on this structure, theoretical models have been proposed for glycoprotein hormone receptors, where the hormone mainly interacts with the inner circumference of the receptor LRR motifs (Jiang et al. 1995, Moyle et al. 1995). However, these models cannot predict how the membrane environment influences the tertiary and secondary structure of the receptor. It has been shown that purified FSHR-ECD undergoes dramatic structural transition when incubated in the presence of detergent micelles (Mahale et al. 2001). Only the crystal 
structure of the hormone-receptor complex defines the actual binding site, and in the absence of this information, a number of strategies have been employed to delineate the hormone-binding sites of the ECD. Therefore, approaches such as the use of synthetic peptides, antipeptide antibodies corresponding to peptide segments of the ECD or alanine-substituted or deletion mutants (Dias et al. 2002) are being extensively employed.

The currently accepted models of gonadotropinreceptor interaction propose that different discrete, discontinuous regions of the ECD of the FSHR govern hormone binding. Whether similar regions in the large ECD of the FSHR are also involved in signal transduction, in addition to hormone binding, is not clear.

In the present study, potential surface-oriented regions, which are believed to be involved in protein-protein interaction, were identified from the ECD of the human (h)FSHR sequence. Synthetic peptides corresponding to these regions were synthesized and tested for their ability to inhibit the binding of hormone to its receptor. The effect of these peptides in signal transduction was also studied. This paper describes the identification of certain discrete, well-defined regions on the ECD of the hFSHR, that appear to govern either FSH binding or signal transduction, or both.

\section{Materials and Methods}

\section{Materials}

Fluorenylmethyloxycarbonyl (Fmoc) amino acids were purchased from Advanced Chemtech (Louisville, KY, USA) or CN Biosciences (San Diego, CA, USA). Rink amide and Rink amide-AM resins were purchased from CN Biosciences. 1,2-Ethanedithiol (EDT) and thioanisole were purchased from Aldrich (Milwaukee, WI, USA). Piperidine was purchased from Merck (Darmstadt, Germany). $\mathrm{Na}^{125} \mathrm{I}$ was purchased from Dupont NEN (Boston, MA, USA). Iodination-grade hFSH and biological grade hFSH and hCG were gifts from the National Hormone and Pituitary Program (Bethesda, MD, USA). DMEM-F12, newborn calf serum, freezing mixtureDMSO, nystatin, trypsin-EDTA and fungisone were purchased from Gibco BRL (Gaithersburg, MA, USA). Penicillin and gentamicin were purchased locally. ATP, magnesium chloride, chloramine- $\mathrm{T}$, succinyl cyclic nucleotide tyrosine methyl ester (ScAM-TME), isobutyl methylxanthine, aprotinin, phenyl methyl sulfonyl fluoride (PMSF) and activated charcoal were purchased from Sigma (St Louis, MO, USA). cAMP antiserum was a gift from Prof. Sandhya Visweswaraiah of Bangalore, India.

\section{Identification of potential surface-oriented regions of hFSHR}

Potential surface-oriented regions of hFSHR-ECD were identified by the computer program Peptide (Krchnak et al. 1987). This program analyzes protein sequences by parameters such as hydrophilicity, accessibility, hydrophobicity, antigenicity, acrophilicity, hydropathy, large-sphere accessibility and presence of $\beta$-turns. The regions which were consistently identified by a majority of the parameters were considered to be potentially surface-oriented in hFSHR-ECD.

\section{Synthesis of peptides}

Assembly of the peptide chain, cleavage of the peptide from the solid support, purification by reversed-phase high performance liquid chromatography and characterization by amino-acid analysis were carried out as described earlier (Jetly et al. 2003).

\section{Radioreceptor assay (RRA)}

RRA was carried out to assess the ability of these peptides to inhibit $\left[{ }^{125} \mathrm{I}\right] \mathrm{hFSH}$ binding to FSHR. Geneticin disulfate (G-418)-resistant human embryonic kidney cells (HEK-293) expressing rat FSHR were used as a source of FSHR. The cells expressing rat FSHR were produced by transfecting HEK-293 cells with full-length FSHR cDNA cloned into pCDNA3 and selecting the cells on a medium containing G-418 $(500 \mu \mathrm{g} / \mathrm{ml})$. The clone expressing FSHR was identified by $\left[{ }^{125} \mathrm{I}\right]$ ovine(o)FSH binding (Nalavadi 2002). The protocol for preparation of particulate membranes enriched by rat FSHR was adapted from the method described by Bramley and Ryan (1978). The protein content was estimated by Bradford's (1976) method.

Radioiodination of hFSH was carried out by the iodogen method (Fraker \& Speck 1978). For competitive displacement, $\left[{ }^{125} \mathrm{I}\right] \mathrm{hFSH}(200000$ c.p.m.; $15-18 \mu \mathrm{Ci} / \mu \mathrm{g})$ in RRA buffer containing $0 \cdot 2 \%$ bovine serum albumin was used as a tracer for binding to FSHR. The RRA was carried out in a reaction volume of $200 \mu \mathrm{l}$. Increasing concentrations of $\mathrm{hFSH}$ or receptor peptide $(50 \mu \mathrm{l})$ were preincubated with $\left[{ }^{125} \mathrm{I}\right] \mathrm{hFSH}(50 \mu \mathrm{l})$ for $1 \mathrm{~h}$ at room temperature. This was followed by addition of receptor preparation (suitably diluted to a volume of $100 \mu \mathrm{l}$ corresponding to approximately $10 \%$ binding of input count, that is, 20000 c.p.m.) and further incubation for $2 \mathrm{~h}$ at room temperature. The assay was terminated by the addition of $300 \mu \mathrm{l}$ RRA buffer and $500 \mu 15 \%$ polyethylene glycol, followed by centrifugation to separate the bound radioactivity from free, at 3000 r.p.m. for $30 \mathrm{~min}$ at $4{ }^{\circ} \mathrm{C}$. The supernatant was decanted, and radioactivity in each pellet determined with a $\gamma$-counter (Wallac 1470 WIZARD, Turku, Finland). All peptides were screened at the highest concentration in human chorionic gonadotropin (hCG) RRA (Selvaraj \& Moudgal 1993). Data were analyzed by the software 'GraphPad Prism 3.0' San Diego, CA, USA. 
Table 1 Amino-acid sequence of potential surface-oriented regions of FSHR-ECD selected for the study by the Peptide program

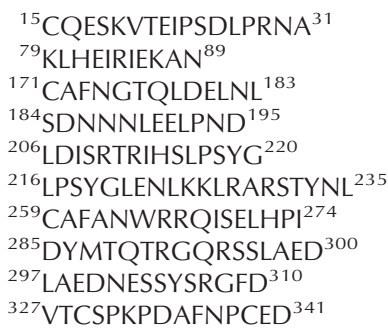

Mechanism of inhibition by peptides of hormone-receptor binding

In order to determine the nature or mechanism of inhibition by peptides with regard to their ability to inhibit hFSH-FSHR binding, the radioreceptor assay was done as follows. Effective peptides at a concentration of $100 \mu \mathrm{g} / 100 \mu \mathrm{l}\left(1 \cdot 08 \times 10^{-4} \mathrm{M}\right.$ and $1 \cdot 14 \times 10^{-4} \mathrm{M}$ for 285-300 and 297-310 hFSHR respectively) were incubated with different doses of hFSH $(100,10,2 \cdot 5,0 \cdot 625$, $0 \cdot 15625$ and $0 \mathrm{ng})$, receptor $(100 \mu \mathrm{l}$; corresponding to a binding of approximately 20000 c.p.m.) and $\left[{ }^{125} \mathrm{I}\right] \mathrm{hFSH}$ $(100 \mu \mathrm{l} ; 200000$ c.p.m.; $25-30 \mu \mathrm{Ci} / \mu \mathrm{g})$ for $2 \mathrm{~h}$ at room temperature. The assay was terminated and radioactivity was measured in the pellets as mentioned previously. Scatchard analysis was done with 'GraphPad Prism $4 \cdot 0$.

In vitro FSH bioassay and RIA for CAMP

The effect of hFSHR peptides on signal transduction was evaluated by in vitro FSH bioassay. A cocktail buffer containing $10 \mathrm{mM} \mathrm{MgCl}$, $1 \mathrm{mM}$ ATP, $10 \mathrm{mM}$ isobutyl methylxanthine and 10\% glycerol in $50 \mathrm{mM}$ HEPES buffer, $\mathrm{pH} 7 \cdot 5$, was used for the assay. The optimum concentration of hFSH required for cAMP production was selected by using different doses of FSH (0.001-100 nM) in a separate assay. An amount of $10 \mathrm{nM} \mathrm{hFSH}$ was selected and further used to challenge the receptor preparation. The effect of each peptide $\left(1 \times 10^{-5} \mathrm{M}\right)$ in the absence of hFSH was studied to look at inherent inhibition or activation. Different concentrations of each peptide $\left(0 \cdot 625 \times 10^{-6}-10 \times 10^{-5} \mathrm{M}\right)$ along with $\mathrm{hFSH}$ were preincubated in the cocktail buffer for $1 \mathrm{~h}$ at $37^{\circ} \mathrm{C}(40 \mu \mathrm{l})$. This was followed by addition of receptor preparation (corresponding to $10 \mu \mathrm{g}$ of protein in $10 \mu \mathrm{l}$ ) and incubation at $37^{\circ} \mathrm{C}$ for $12 \mathrm{~min}$ (optimal time determined separately in a series of time-course experiments). The reaction was terminated by addition of $450 \mu \mathrm{l}$ of ice-cold $50 \mathrm{mM}$ sodium acetate buffer, $\mathrm{pH} 4 \cdot 3$, and followed by boiling for
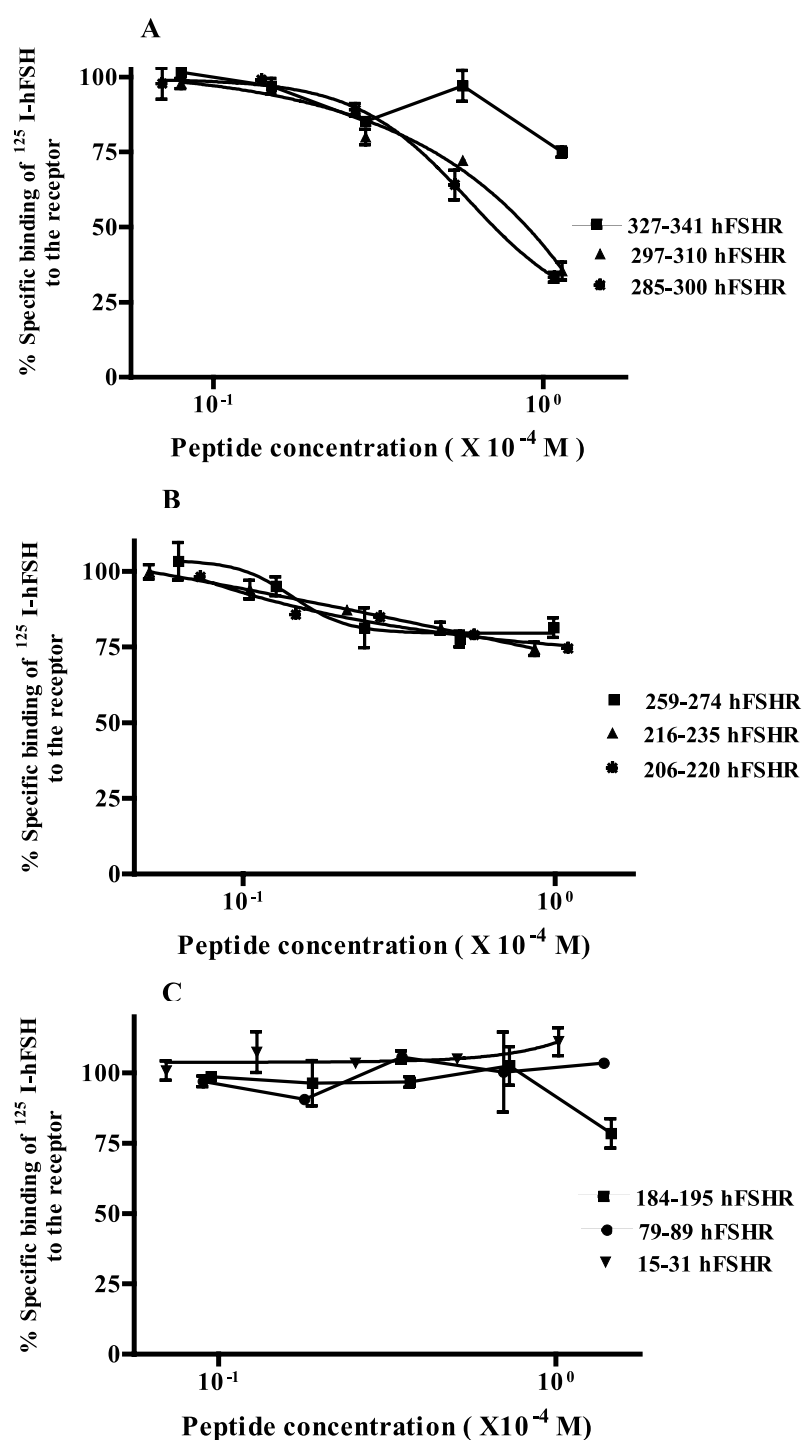

Figure 1 Inhibition of $\left[{ }^{125}\right.$ I]hFSH binding to FSHR by synthetic peptides corresponding to hFSHR sequences. (A) 327-341, 297-310 and 285-300; (B) 259-274, 216-235 and 206-220; (C) 184-195, 79-89 and 15-31. Peptides at various concentrations were incubated with labeled hFSH (200 000 c.p.m./tube per $50 \mu \mathrm{l})$ at room temperature for $1 \mathrm{~h}$, followed by addition of HEK-293 cell membrane expressing FSHR $(10 \mu \mathrm{g}$ protein/100 $\mu \mathrm{l})$. Nonspecific binding was determined in the presence of $1 \mu \mathrm{g}$ of unlabeled FSH $(100 \mu \mathrm{l})$. Each point represents the mean \pm S.D. of three independent experiments carried out in triplicate.

10 min. The cAMP produced was assayed by the cAMP RIA (Shenoy et al. 2003). For this purpose, succinyl cyclic nucleotide tyrosine methyl ester was iodinated by the chloramine-T method and isolated by descending paper chromatography (Brooker et al. 1978). Data were analyzed by 'GraphPad Prism 4·0'. 


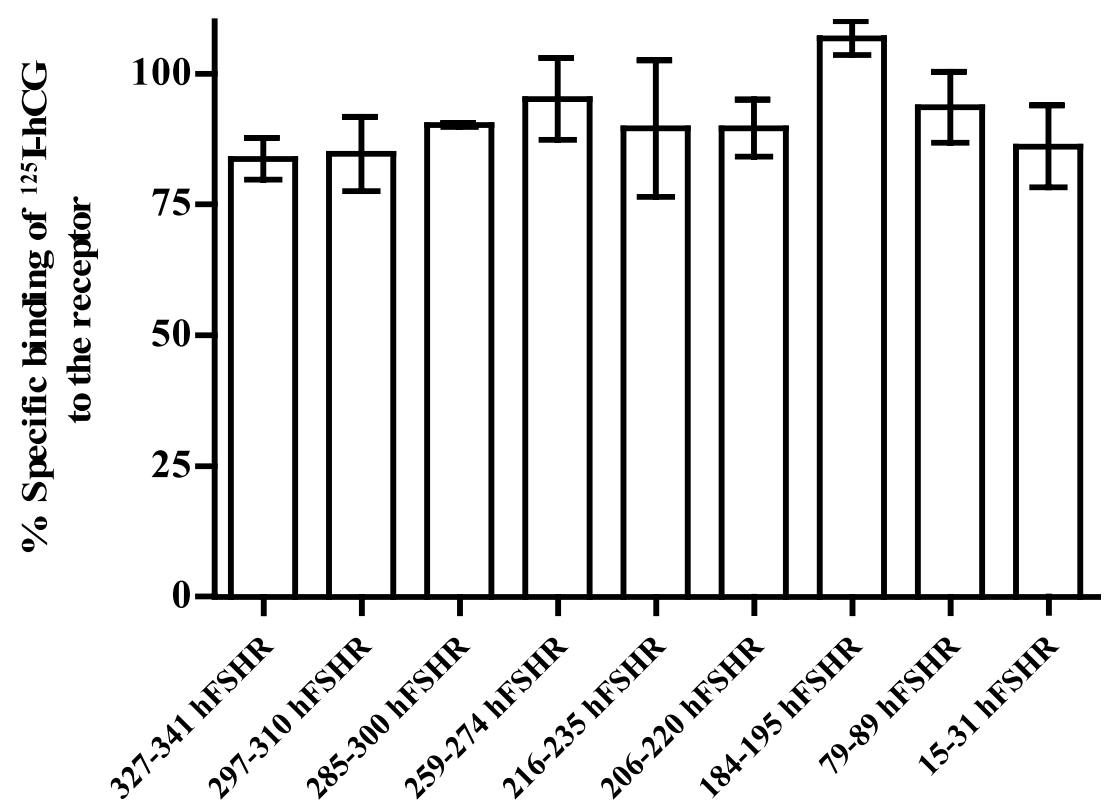

Figure 2 Synthetic peptides corresponding to hFSHR sequences studied exhibit no effect on [ ${ }^{125}$ I] hCG binding to LH/CGR. Peptides corresponding to maximum concentration as used in FSH-RRA were incubated with labeled hCG (200 000 c.p.m./tube per $100 \mu \mathrm{l}$ ) at room temperature for $1 \mathrm{~h}$, followed by addition of rat testicular membrane preparation $(100 \mu \mathrm{l})$. Nonspecific binding was determined in the presence of $1 \mu \mathrm{g}$ of unlabeled hCG. Values represent the mean \pm S.D. of two independent experiments carried out in duplicate.

\section{Results}

Identification of potential surface-oriented regions of the ECD of $h F S H R$ and their synthesis

Analysis of the hFSHR-ECD sequence with the 'PEPTIDE' program resulted in the identification of regions 15-31, 79-89, 171-183, 184-195, 206-220, 216-235, 259-274, 285-300, 297-310 and 327-341 by a majority of parameters as having the potential to be surface oriented (Table 1). All 10 peptides were obtained in good yield. Amino-acid analysis confirmed the presence of all the required amino acids in the expected ratios for the peptides. The molecular masses of the peptides as determined by MALDI-TOF mass spectrometry were in accordance with the expected values.

\section{Effect of peptides in $R R A$}

All peptides except peptide 171-183 hFSHR were screened in the hFSH RRA to determine whether they affected binding of $\left[{ }^{125} \mathrm{I}\right] \mathrm{hFSH}$ to the receptor (Fig. 1). Peptide 171-183 hFSHR was insoluble in the RRA buffer and could not be tested. Only two peptides, 285-300 hFSHR and 297-310 hFSHR, inhibited binding of $\left[{ }^{125} \mathrm{I}\right] \mathrm{hFSH}$ to HEK-FSHR cells in a dose-dependent manner. IC $_{50}$ values for peptides $285-300$ and 297-310 were found to be $0.38 \times 10^{-4} \mathrm{M}$ and $0.40 \times 10^{-4} \mathrm{M}$ respectively $\left(\mathrm{IC}_{50}\right.$ is defined as the concentration of peptide required to inhibit the binding of $\left[{ }^{125} \mathrm{I}\right] \mathrm{hFSH}$ to the receptor by $50 \%$ ). The effect was specific to FSHR, as these peptides at the highest concentration did not inhibit binding of labeled hCG to the sheep LH/chorionic gonadotropin (CG)R (Fig. 2).

\section{Mechanism of inhibition of hFSH-FSHR binding}

Both peptides act as weak competitive inhibitors of hFSHFSHR binding, altering both $K_{\mathrm{D}}$ and $\mathrm{B}_{\max }$ of hFSH, but not to a greatly significant level in comparison to the value in the absence of any peptide (Fig. 3). The inhibitory effect is reversed in the presence of higher concentrations of unlabeled hFSH, as evidenced by the nature of the Scatchard plot, indicating that both peptides do indeed function as competitive inhibitors.

\section{Effect of peptides on FSH-induced adenylyl cyclase activity}

All peptides except peptide 171-183 (insoluble in cocktail buffer) were screened for their ability to inhibit FSHresponsive adenylyl cyclase using HEK-FSHR membrane preparation. Peptides by themselves at a concentration of $10 \mu \mathrm{M}$ did not stimulate or inhibit basal adenylyl cyclase activity in HEK-FSHR membranes (Fig. 4). Of the nine peptides screened, peptides 15-31, 79-89, 184-195, 216235 and 285-300 hFSHR were found to inhibit FSHresponsive adenylyl cyclase in a dose-dependent manner 


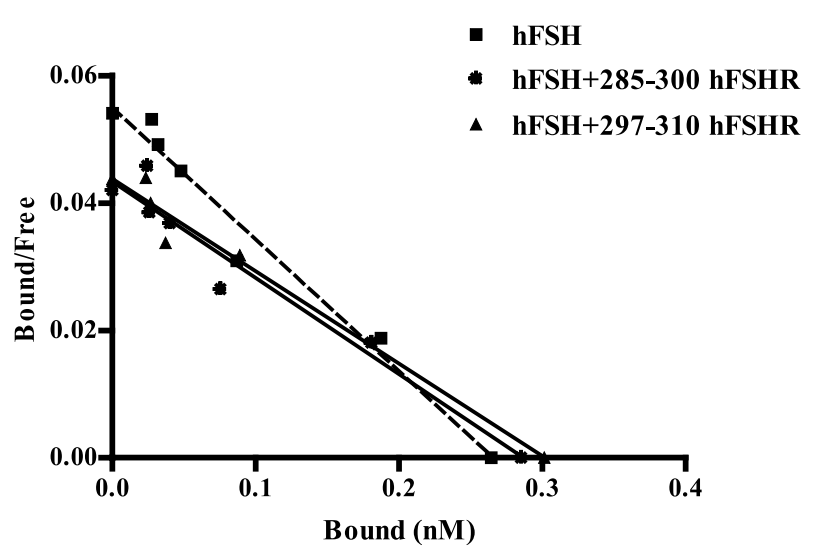

Figure 3 Scatchard analysis to study the mechanism of inhibition of peptides 285-300 and 297-310 hFSHR on binding of hFSH to FSHR. Peptides $\left(1.14 \times 10^{-4} \mathrm{M}\right.$ and $1.07 \times 10^{-4} \mathrm{M}$ for peptides 285-300 and 297-310 hFSHR respectively) were incubated with different doses of hFSH, $\left[{ }^{125} \mathrm{I}\right] \mathrm{hFSH}$ (200 000 c.p.m., $25-30 \mu \mathrm{Ci} / \mu \mathrm{g})$ and receptor membrane $(100 \mu \mathrm{l})$. Each point represents the mean \pm S.D. of three independent experiments carried out in triplicate. For hFSH, hFSH+285-300 hFSHR and $\mathrm{hFSH}+297-310 \mathrm{hFSHR}$, the $\mathrm{B}_{\max }(\mathrm{nM})$ values are $0.06127,0.0633$ and 0.07453 respectively, while the $K_{\mathrm{D}}(\mathrm{nM})$ values are 0.07347 , 0.08353 and 0.111 respectively.

with $\mathrm{IC}_{50}$ values of $8.96 \times 10^{-6} \mathrm{M}, 7.58 \times 10^{-6} \mathrm{M}$, $9.48 \times 10^{-6} \mathrm{M}, \quad 9.73 \times 10^{-6} \mathrm{M}$ and $4.80 \times 10^{-6} \mathrm{M}$ respectively (Fig. 5).

\section{Discussion}

This study aimed to delineate regions on the extracellular domain of hFSHR involved in FSH binding and/or ensuing signal generation in terms of release of cAMP. Different regions from the extracellular domain of LH/CGR (Roche et al. 1992) and thyroid-stimulating hormone receptor (TSHR) (Morris et al. 1993) have been identified by the synthetic peptide strategy as being involved in hormone binding. Attempts were made in the past to study different regions from the ECD of FSHR by the synthetic peptide approach (Mahale et al. 2001). However, a complete analysis was lacking mainly due to the insolubility of some of the peptides in the assay buffer, as the peptides selected were based on leucine-rich repeat sequence.

The currently accepted model of FSH-FSHR interaction suggests that the $\mathrm{N}$-terminal and $\mathrm{C}$-terminal ends of FSHR-ECD have little role in stabilizing this interaction (Dias et al. 2002). FSH is predicted to dock centrally to the predicted $\beta$-sheet on the concave surface of the FSHR model. In the absence of the three-dimensional structure of the FSH-FSHR complex, it is assumed that different residues on the ECD come into play at different points in the receptor activation. Thus, FSHR can be envisioned to be in a relatively flexible form in the membrane, which upon hormone binding undergoes a conformational change that leads ultimately to cAMP production.

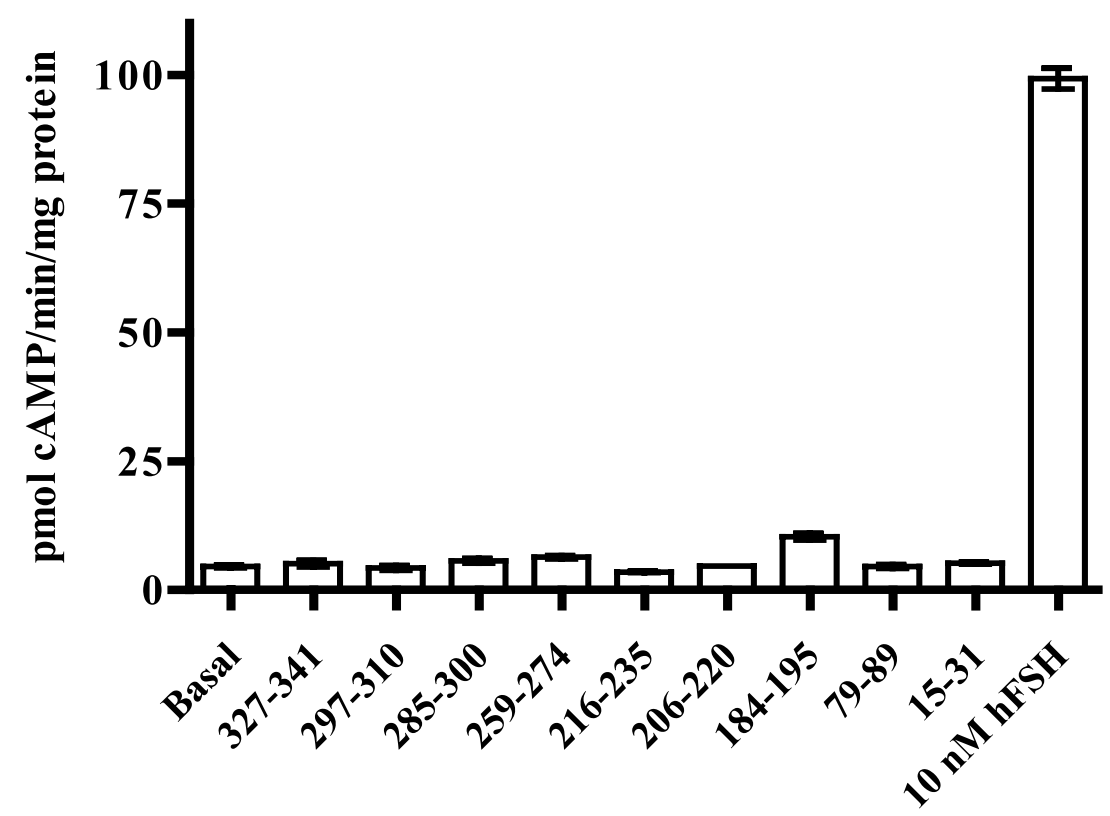

Figure 4 Effect of peptides $\left(1 \times 10^{-5} \mathrm{M}\right.$ each) on the activation of adenylyl cyclase in the absence of hFSH. All peptides were incubated with the HEK-293 cell membranes expressing FSHR in the absence of hFSH. cAMP released was measured by RIA. CAMP levels measured at basal and in response to $10 \mathrm{nM} \mathrm{hFSH}$ are also indicated. Values represent the mean \pm S.D. of two independent experiments carried out in triplicate. 


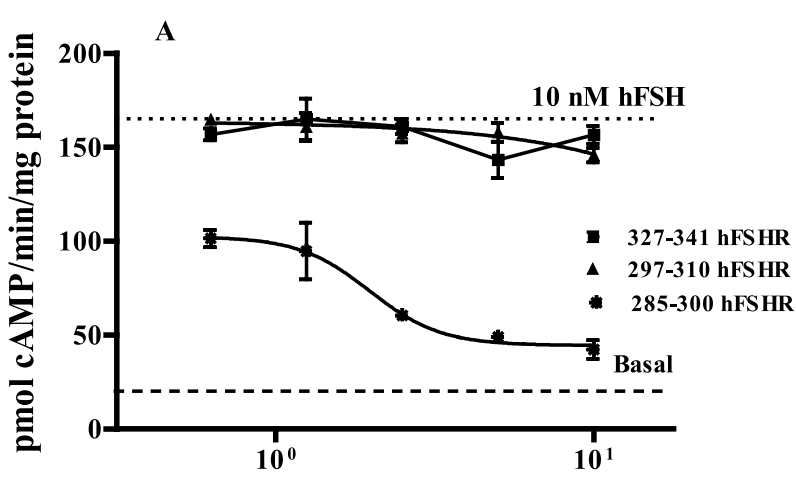

Peptide concentration ( $\mathrm{X} \mathrm{10}^{-6} \mathrm{M}$ )
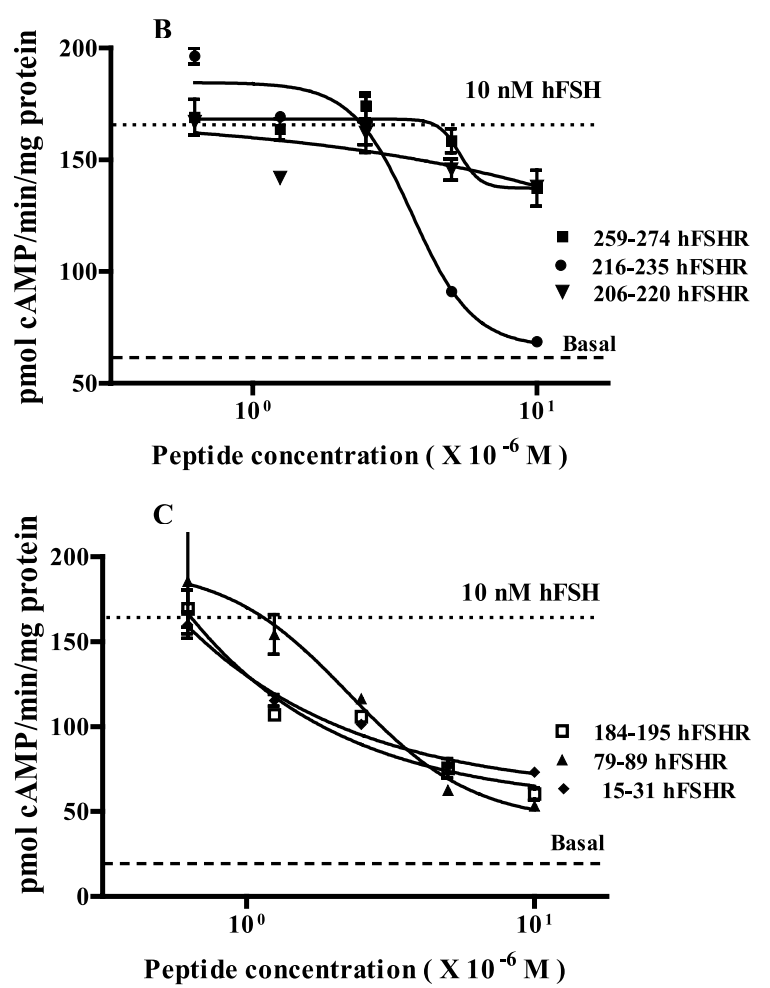

Figure 5 Effect of different peptides of hFSHR on FSH-induced activation of adenylyl cyclase. (A) 327-341, 297-310 and 285-300 hFSHR; (B) 259-274, 216-235 and 206-220 hFSHR; (C) 184-195, 79-89 and 15-31 hFSHR. HEK-293 cell membranes expressing FSHR were stimulated with $10 \mathrm{nM}$ hFSH in the presence of different doses of the peptides $\left(0.625 \times 10^{-6}-1 \times 10^{-5} \mathrm{M}\right)$. CAMP released was measured by RIA. cAMP levels measured at baseline and in response to $10 \mathrm{nM}$ $\mathrm{hFSH}$ are indicated by dotted lines. Each point represents the mean \pm S.D. of three independent experiments carried out in triplicate.

The N-terminus is believed to harbor a probable hormone-binding site and/or membrane localization signal (Nechamen et al. 2000). Earlier studies employing the synthetic peptide strategy (Dattatreyamurty et al. 1992) and antipeptide antibodies (Dattatreyamurty et al. 1993) indicated that region 9-30 was responsible for hormone binding. Regions 265-296 of rat and human FSHR (Liu et al. 1994) and 309-322 of hFSHR (Zijlstra-Westhoff et al. 1998) have been suggested to be hormone-binding sites on account of being accessible to antipeptide antibodies. The impetus has largely been on the leucine-rich repeat structures, which form the core region of hFSHRECD and have been suggested to be essential for hormone binding (Schmidt et al. 2001). Region 300-315 of rat FSHR was shown to interact directly with specific regions of hFSH $\beta$ (Leng et al. 1995), while 300-315 of hFSHR has been identified as being accessible to monoclonal antibodies (Lindau-Shepard et al. 2001). From its propensity to inhibit hFSH binding, prevent signal transduction and form an ordered secondary structure in the presence of dodecyl phosphocholine, hFSHR region $221-252$ has also been thought to be in close contact with the cell membrane (Mahale et al. 2001).

Assuming that multiple linear, discrete epitopes on the ECD of hFSHR are crucial for hormone binding and signal transduction, we assessed the ability of each peptide to modulate both parameters. Peptides $285-300$ and 297-310 hFSHR were observed to inhibit binding of hFSH to FSHR in a dose-dependent manner. Both peptides were highly specific with reference to FSHFSHR interaction. The sequence 285-296 from the region 285-300 forms a part of the region 265-296 from FSHR previously shown to be accessible to antipeptide antibodies (Liu et al. 1994), but presumed to be unimportant for ligand contact and activation (Liu et al. 2000). Antipeptide antibodies may prevent binding of FSH to its receptor through steric hindrance. Hence, whether the region 265-296 is in close proximity to hormone-binding sites or is part of the hormone-receptor interface is not clear. Whether the inclusion of sequence residues as in 265-284 could lead to contrary results is also a matter of speculation. Region 285-300 hFSHR has no homology with its corresponding regions from hLHR and hTSHR, indicating a unique sequence and a probable determinant of hormone specificity. This stretch also has a potential $\beta$-turn, and is the only region that is positive for nine of the 10 parameters in the PEPTIDE program, indicative of probable surface orientation (Krchnak et al. 1987) and further strengthening a possible role in protein-protein interaction.

Sequence 297-310 contains the sequence 300310 hFSHR previously suggested to be surface oriented, but not critical for hormone binding and near the hormone-binding site (Lindau-Shepard et al. 2001). This sequence has a single conserved residue, glutamine at position 301, in contrast to the analogous regions from hLHR and hTSHR, suggestive of a putative determinant of hormone specificity.

Interestingly, the region $285-310 \mathrm{hFSHR}$ represents novel and unique domains in comparison to the domains identified on LH/CGR and TSHR by the 


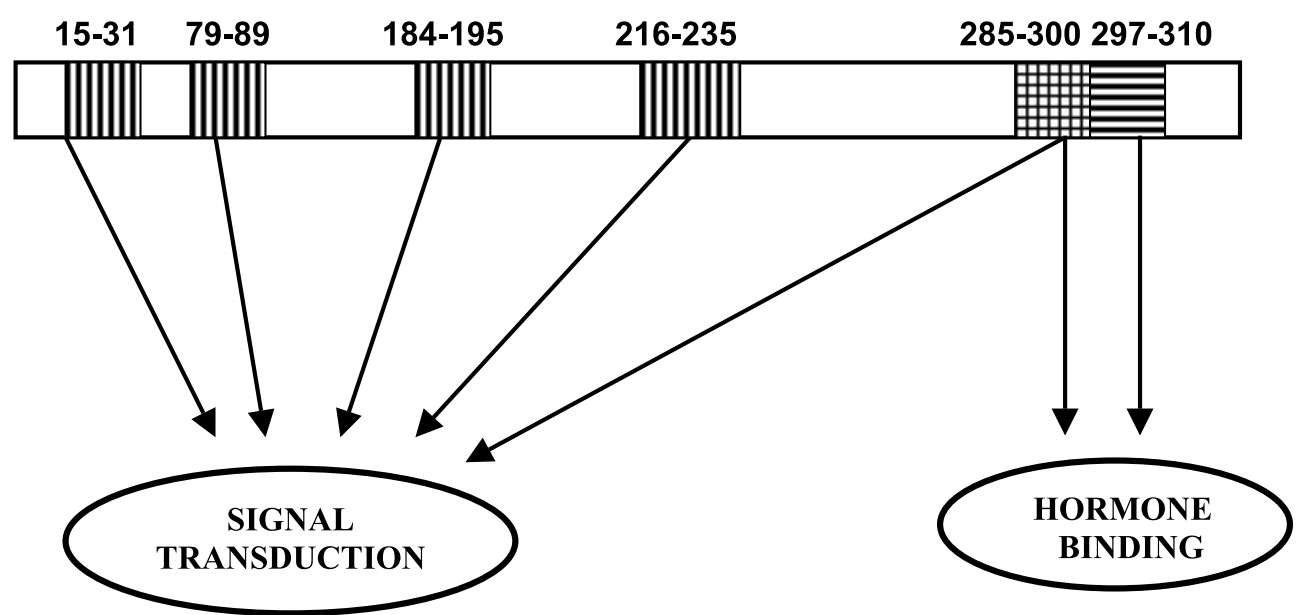

Figure 6 Schematic representation of the potential regions of ECD involved in FSH binding and/or signal transduction.

synthetic peptide approach (Roche et al. 1992, Morris et al. 1993).

Although peptide 9-30 of rat FSHR had been previously demonstrated to inhibit hormone binding in a dose-dependent manner (Dattatreyamurty et al. 1992.), we could not demonstrate similar observations with peptide 15-31 hFSHR, which forms a part of this sequence, emphasizing the critical effects contributed by the charge and position of a single or a few amino acids.

Both peptides 285-300 hFSHR and 297-310 hFSHR also function as weak competitive inhibitors of binding of $\mathrm{hFSH}$ to its receptor, further showing that these regions are crucial determinants of hormone binding. The weak nature of inhibition can be explained by the basic assumption that different discrete regions of the ECD are responsible and required for hormone binding and signal transduction.

The actual role, if any, played by the ECD in governing signal generation is speculative. Previous studies have concentrated on the site-directed mutagenesis approach to delineate region 19-29 of rat FSHR as crucial in signal transduction (Mann et al. 2000). Peptide 221-252 hFSHR has also been shown to inhibit signal transduction in Y1 cells expressing hFSHR (Mahale et al. 2001). We have attempted to look at the effect of these peptides in inhibiting signal transduction by measuring FSH-induced cAMP release. Peptides 15-31 hFSHR, 79-89 hFSHR, 184-195 hFSHR, 216-235 hFSHR and 285$300 \mathrm{hFSHR}$ were observed to be functional in this aspect. Peptides other than 15-31 hFSHR and 285-300 hFSHR map to the predicted LRR region of the ECD (Dias et al. 2001). It is very interesting to note that, except for peptide 285-300 hFSHR $\left(\mathrm{IC}_{50}=4.8 \times 10^{-6} \mathrm{M}\right)$, none of the other active peptides were able to inhibit binding of hormone to the receptor, as observed in FSH-RRA.
These regions could represent secondary binding sites, exposed as a result of a conformational change due to initial binding of hormone to the receptor. Although it has been suggested that the LRR region of ECD is crucial to hormone binding, while the $\mathrm{C}$ and $\mathrm{N}$ termini are unimportant, our results suggest the contrary. Together, these results underscore that multiple linear, discrete epitopes on the ECD of hFSHR are crucial for hormone binding or signal transduction, or both.

This is the first study done by the synthetic peptide strategy to find all the regions of the ECD of hFSHR crucial for hormone binding and signal transduction. In effect, we have identified potential surface-oriented regions on the ECD of hFSHR that could be instrumental in governing hormone binding and the ensuing signal transduction (Fig. 6). Of all the regions studied, peptide 285-300 hFSHR represents a unique, specific sequence with the potential to be surface oriented as a novel candidate locus crucial to both FSH binding and signal generation.

\section{Acknowledgements}

The research work related to this paper (NIRRH/MS/ 01/2004) was supported by grants from the Indian Council of Medical Research and Department of Atomic Energy, Government of India. The award of junior and senior research fellowships to PSK by the Council of Scientific and Industrial Research is gratefully acknowledged. We thank Dr C P Puri, the director of our institute, for his constant support and encouragement; Ms L V Tendulkar and Ms V H Nakhawa for technical assistance; and the National Hormone and Pituitary Program, USA, for the supply of iodination and biological grade hFSH and hCG. 


\section{References}

Bradford MM 1976 A rapid and sensitive method for the quantitation of microgram quantities of protein utilizing the principle of protein-dye binding. Analytical Biochemistry 72 248-254.

Bramley TA \& Ryan RJ 1978 Interactions of gonadotropins with corpus luteum membranes. VII. Association of hCG-binding and adenylate cyclase activities with rabbit corpus luteum plasma-membranes. Molecular and Cellular Endocrinology 12 319-325.

Braun T, Schofield PR \& Sprengel R 1991 Amino terminal leucine-rich repeats in gonadotropin receptors determine hormone selectivity. EMBO Journal 10 1885-1890.

Brooker G, Harper JF, Terasaki WL \& Moylan RD 1979 Radioimmunoassay of cyclic AMP and cyclic GMP. Advances in Cyclic Nucleotide Research 10 1-33.

Dattatreyamurty B \& Reichert LE Jr 1992 A synthetic peptide corresponding to amino acids 9-30 of the extracellular domain of the follitropin (FSH) receptor specifically binds FSH. Molecular and Cellular Endocrinology 87 9-17.

Dattatreyamurty B \& Reichert LE Jr 1993 Functional properties of polyclonal antibodies raised against the $\mathrm{N}$-terminus region (residues 9-30) of the follicle-stimulating hormone (FSH) receptor: significance of this region in FSH recognition and signal transduction. Endocrinology 133 1593-1601.

Dias JA \& Van Roey P 2001 Structural biology of human follitropin and its receptor. Archives of Medical Research 32 510-519.

Dias JA, Cohen B, Lindau-Shepard B, Nechamen CA, Peterson AJ \& Schmidt A 2002 Molecular, structural and cellular biology of follitropin and follitropin receptor. Vitamins and Hormones 64 249-322.

Foulkes NS, Schlotter F, Pevet P \& Sassone-Corsi P 1993 Pituitary hormone FSH directs the CREM functional switch during spermatogenesis. Nature 362 264-267.

Fraker PJ \& Speck JC Jr 1978 Protein and cell membrane iodinations with a sparingly soluble chloroamide,1,3,4,6-tetrachloro-3a,6adiphenylglycoluril. Biochemical and Biophysical Research Communications 80 849-857.

Jetly NM, Iyer KS, Hosur MV \& Mahale SD 2003 Attempt to map the receptor binding sites of human follicle-stimulating hormone using disulfide peptides of its beta-subunit indicates major involvement of the regions around disulfide bonds Cys 28-Cys 82 and Cys 32-Cys 84 in receptor binding of the hormone. Journal of Peptide Research 62 269-279.

Ji I \& Ji TH 1991 Exons 1-10 of the rat LH receptor encode a high affinity hormone binding site and exon 11 encodes G-protein modulation and a potential second hormone binding site. Endocrinology 128 2648-2650.

Jiang X, Dreano M, Buckler DR, Cheng S, Ythier A, Wu H, Hendrickson WA \& Tayar NE 1995 Structural predictions for the ligand-binding region of the glycoprotein hormone receptors and the nature of hormone-receptor interactions. Structure $\mathbf{1 5}$ 1341-1353.

Kobe B \& Deisenhofer J 1994 The leucine-rich repeat: a versatile binding motif. Trends in Biochemical Sciences 19 415-421.

Krchnak V, Mach O \& Maly A 1987 Computer prediction of potential immunogenic determinants from protein amino acid sequence. Analytical Biochemistry 165 200-207.

Leng N, Dattatreyamurty B \& Reichert LE Jr 1995 Identification of amino acid residues $300-315$ of the rat FSH receptor as a hormone binding domain: evidence for its interaction with specific regions of FSH beta-subunit. Biochemical and Biophysical Research Communications 210 392-399.

Lindau-Shepard B, Brumberg HA, Peterson AJ \& Dias JA 2001 Reversible immunoneutralisation of the human follitropin receptor. Journal of Reproductive Immunology 49 1-19.

Liu X, Depasquale J, Griswold M \& Dias JA 1994 Accessibility of rat and human follitropin receptor primary sequence (R265-S296) in situ. Endocrinology 135 682-691.
Liu X, Butterstein GM, Lindau-Shepard B, Brumberg HA \& Dias JA 2000 An FSH receptor ectodomain that is a target for receptor immunoneutralisation yet does not affect ligand contact and activation. Endocrine 13 361-367.

Mahale SD, Cavanagh J, MacColl R, Schmidt A, Lindau-Shepard B \& Dias JA 2001 Autologous biological response modification of gonadotropin receptor. Journal of Biological Chemistry 276 12410-12419.

Mann KI, Liu X \& Dias JA 2000 Deletion of follicle-stimulating hormone (FSH) receptor residues encoded by exon one decreases FSH binding and signaling in rat. Biology of Reproduction 62 1240-1247.

McFarland KC, Sprengel R, Phillips HS, Kohler M, Rosemblit N, Nikolics K, Segaloff DL \& Seeburg PH 1989 Lutropin-choriogonadotropin receptor: an unusual member of the G-protein coupled receptor family. Science 245 494-499.

Morris JC, Bergert ER \& McCormick DJ 1993 Structure-function studies of the human thyrotropin receptor: inhibition of binding of labeled thyrotropin (TSH) by synthetic human TSH receptor peptides. Journal of Biological Chemistry 268 10900-10905.

Moyle WR, Campbell RK, Venkateswara Rao SN, Ayad NG, Bernard MP, Han Y \& Wang Y 1995 Model of human chorionic gonadotropin and lutropin receptor interaction that explains signal transduction of the glycoprotein hormones. Journal of Biological Chemistry $27020020-20031$.

Nalavadi VC 2002 Structure-function studies on rat follicle stimulating hormone receptor using immunological probes. $\mathrm{PhD}$ thesis, Indian Institute of Science, Bangalore, India.

Nechamen CA \& Dias JA 2000 Human follicle stimulating hormone receptor trafficking and hormone binding sites in the amino terminus. Molecular and Cellular Endocrinology 166 101-110.

Reichert LE Jr \& Dattatreyamurty B 1989 The follicle-stimulating hormone (FSH) receptor in testis: interaction with $\mathrm{FSH}$, mechanism of signal transduction and properties of the purified receptor. Biology of Reproduction 40 13-26.

Richards JS 1980 Maturation of ovarian follicles: actions and interactions of pituitary and ovarian hormones on follicular cell differentiation. Physiological Reviews 60 51-89.

Roche PC, Ryan RJ \& McCormick DJ 1992 Identification of hormone-binding regions of the human luteinising hormone/human chorionic gonadotropin receptor using synthetic peptides. Endocrinology 131 268-274.

Schmidt A, MacColl R, Lindau-Shepard B, Buckler D \& Dias JA 2001 Accessibility and structural analysis of the purified soluble binding unit of follitropin receptor complexed with single chain follitropin. Journal of Biological Chemistry 276 23373-23381.

Selvaraj N \& Moudgal NR 1993 Development of an LH receptor assay capable of measuring serum LH/CG in a wide variety of species. Journal of Reproduction and Fertility 98 611-616.

Sharma SC \& Catterall JF 1995 Expression of the extracellular domain peptides of the FSH receptor and their effect on receptor-ligand interactions in vitro. Molecular and Cellular Endocrinology 115 87-93.

Shenoy AR, Srinivasan N, Subramaniam M \& Visweswariah SS 2003 Mutational analysis of the Mycobacterium tuberculosis Rv1625c adenylyl cyclase: residues that confer nucleotide specificity contribute to dimerization. FEBS Letters 545 253-259.

Zijlstra-Westhoff WE, Slootstra JW, Pujik WC, Schaaper WMM, Oonk HB \& Meloen RH 1998 In vitro inhibition of the bioactivity of follicle-stimulating hormone by antisera against a peptide representing part of the FSH-receptor. Journal of Reproductive Immunology 38 139-154.

Received in final form 27 May 2004

Accepted 18 June 2004

Made available online as an

Accepted Preprint 30 June 2004 